\title{
Role of Endocannabinoids in Neuron-Glial Crosstalk
}

\author{
Livio Luongo, Enza Palazzo, Vito de Novellis and Sabatino Maione*
}

Department of Experimental Medicine - Division of Pharmacology “L. Donatelli”; Second University of Naples, Italy.

\begin{abstract}
Evidence shows bidirectional crosstalk between neurons and glia, suggesting that glia play an active role in synaptic plasticity leading to chronic pain. Importantly, gliosis has been implicated in the development and maintenance of hyperalgesia or allodynia following chronic inflammation or nerve injury. Anandamide (AEA) and 2arachidonoylglycerol (2-AG), or the lipoamino acid $N$-arachydonoyldopamine (NADA), are fatty acid derivative neurotransmitters, named endocannabinoids (eCBs). These perform several biological actions, via the activation of cannabinoid type 1 and 2 (CB1/CB2) receptors belonging to the G-protein-coupled receptor family. The eCBs are produced on demand by neurons or glial cells and it has been suggested that they might be involved in the crosstalk between astrocytes, microglia, oligodendrocytes and neurons. In chronic pain, the modified glial or neural activity also seems to be associated with changes in eCB levels in pain processing areas either in the spinal cord or the brain. The activation of the eCB system in microglia or astrocytes could be crucial in modulating axonal growth and synaptogenesis at the base of neural phenotypic changes. Furthermore, changes in eCBs levels have been suggested to affect the destiny of cells: death or survival may depend on a specific pain condition. Thus, although eCBs are emerging as neurotransmitters responsible for the regulation of glia-neuron crosstalk in chronic pain, the precise mechanisms leading to eCB production, the origin and the timecourse of $\mathrm{eCB}$ release, the $\mathrm{eCB}$ release switch from one cell type to the other and their movement or catabolism across the glial or neural cell membrane nevertheless still remain unknown. These issues together with alternative eCB targets will be addressed in the current review.
\end{abstract}

Key words: Glia-neuron crosstalk, endocannabinoids, anandamide, 2-arachidonoylglycerol, chronic pain.

\section{INTRODUCTION}

Neuropathic pain is a debilitating condition which has a serious impact on the quality of life. It is a devastating and difficult-to-manage consequence of injury to the peripheral or central nervous systems (PNS or CNS) that results in the enhanced transmission of pain messages [1, 2]. Consequently, noxious stimuli are perceived as more painful (hyperalgesia), whereas normal, harmless stimuli elicit pain (allodynia). Therefore, neuropathic pain constitutes a real dysfunction of the nervous system that is characterized by as yet poorly-defined neurophysiological changes. Very few pharmacological strategies exist to treat neuropathic pain, which is very often refractory even to morphine and its derivatives, possibly because it is associated with plastic rearrangements of nociceptive pathways at both spinal and supraspinal level.

Among the pharmacological strategies that have been suggested for neuropathic pain management, the activation of cannabinoid receptors, either directly by natural or synthetic agonists, or indirectly by selective inhibitors of the inactivation of endogenous cannabinoids receptor ligands (endocannabinoids), is widely supported by recent preclinical studies in animal models [3-5]. Evidence shows that cannabinoid receptor agonists can be effective in several

*Corresponding Author: Sabatino Maione, Department of Experimental Medicine - Section of Pharmacology, Second University of Naples, via S. Maria di Costantinopoli, 16 - 80138 Naples, Italy; Tel: +39 081 5667650; Fax: +39081 5667503; E-mail: sabatino.maione@unina2.it animal models of neuropathic pain [3, 6-10]. However, in spite of evidence that neuropathic pain leads to increased endocannabinoid levels at spinal and supraspinal sites [11], the role of endocannabinoids within the brain "pain matrix" need to be further clarified.

Until recently, pain had been thought to arise primarily from the dysfunction of neurons. Recent evidence, however, suggests that neuroimmune changes might contribute to pain following injury to the nervous system as well. Glial cells involved in mediating inflammatory processes are resident within the spinal cord and include both astroglia and microglia, the latter of which has been directly implicated in the initiation of peripheral injury-induced pain [12]. Moreover, microglia have been shown to express cannabinoid receptors [13-16], and to produce and inactivate endocannabinoids $[15,17,18]$.

\section{THE ENDOCANNABINOID SYSTEM AND PATHO- LOGICAL PAIN}

Among the several neurotransmitters that have been suggested to be involved in neuropathic pain, endocannabinoids have been strongly highlighted and heavily investigated over the last decade. The endocannabinoid system consists of the G-protein coupled cannabinoid (CB) receptors, CB1 and $\mathrm{CB} 2$, the endogenous ligand anandamide (arachidonoylethanolamide, AEA) and 2-arachidonoylglycerol (2-AG), and their synthetic and metabolic machinery [19]. The CB1 receptor is localized preferentially in several brain areas such as periaqueductal grey (PAG), cerebellum, hippocampus, cortex). Despite the general opinion which had up until re- 
cently believed CB2 receptors to be exclusively expressed in peripheral tissues and inflammatory cells [20-23], there is now convincing evidence to suggest that they are also expressed in the CNS [24]. Indeed, an increased expression of CB2 receptors has been shown in microglial cells, as well as in astrocytes, in neuropathic pain conditions [25, 26]. It has been underlined that $\mathrm{CB} 2$ receptors play a crucial role in the regulation of central immune responses during neuropathic pain $[27,28]$. Besides the well characterized CB1 and CB2 receptors, several reports have shown the existence of other receptors that represent potential targets to be included in the endocannabinoid system (eCBSS). Thus, the orphan G protein-coupled receptor 55 (also called GPR55) could represent a third CB receptor [29-32]. However, studies performed so far remain inconsistent and further efforts are required to link GPR55 to the eCBSS. Another receptor identified that could belong to the eCBSS is the abnormal-cannabidiol (abn-CBD) receptor (also known as anandamide receptor) [33]. This receptor, also found in microglial cells, is activated by abn-CBD while cannabidiol (CBD) antagonizes it $[33-35,15]$. The endocannabinoid system includes lipid transmitters serving as endogenous ligands for the cannabinoid receptors, and the enzymes for their biosynthesis and inactivation. The first endocannabinoid to be discovered was the $N$-arachidonoyl-ethanolamine (AEA), also called anandamide from the Sanskrit "internal bliss" [36]. This finding was followed by the observation that an already known endogenous metabolite, 2-arachidonoyl-glycerol (2-AG), also exhibits high affinity with CB1 and CB2 receptors [36, 37]. Anandamide, which is synthesized by a phospholipase D (NAPE-PLD) specific for N-acylphosphatidylethanolamine binds both CB1 and CB2 receptors and behaves mostly as a partial agonist [38-40]. Biological inactivation of anandamide occurs through a rapid uptake followed by intracellular hydrolysis mediated by the enzyme fatty acid amide hydrolase (FAAH) [41]. 2-AG, which is more abundant than anandamide in the brain [42], binds to CB1 and CB2 with a lower affinity than anandamide but behaves like a full agonist since it shows higher intrinsic activity [37, 43, 42, 15]. 2-AG is synthesized by the enzyme diacylglycerol lipase (DGL) in a $\mathrm{Ca}^{2+}$-dependent pathway $[44,45]$. Other alternative mechanisms of 2-AG synthesis have also been proposed [46]. Biological inactivation occurs through uptake followed by hydrolysis mediated by the enzyme monoacylglycerol lipase (MGL). Other enzymes have been indicated for 2-AG metabolism, including cyclooxygenases (COXs), lipooxygenases (LOXs) and FAAH [47, 48].

The first evidence of the analgesic properties of cannabis was observed in 1899 by Ernest Dixon [49]. In the last few decades, scientists have focused their attention on the endocannabinoid system in the treatment of chronic and neuropathic pain. Indeed an increasing amount of evidence shows that the cannabinoid receptor system is involved in the pathogenesis of various pain states. CB1 receptor mediated analgesia is associated with adverse psychoactive effects such as sedation, dependence, cognitive impairment and psychotic-like behaviour [50,51], due to the overall activation of this ubiquitous receptor. However, CB2 receptor stimulation is also effective in alleviating inflammatory [52$54,10]$ and neuropathic pain [25, 55-59]. Intriguingly, the CB2-mediated antinociceptive effects seem devoid of any central action (which are CB1 receptor-mediated), and are likely mediated by several mechanisms, and peripheral sites of action of CB2 agonists in both inflammatory and neuropathic pain models have been recognized $[52,53,55,56]$. Among these, a peripheral release of endogenous opioids from keratinocytes has also been shown [55, 56]. Conversely, other evidence shows that the release of endogenous opioids is not involved in CB2 agonist-mediated analgesia in a model of neuropathic pain, [57]. On the other hand, more recent studies have shown the involvement of CB2 receptors within the central nervous system in the analgesic effect of CB2 agonists in neuropathic pain models [60, 61]. These data are supported by reports demonstrating an up-regulation of CB2 receptor mRNA and/or protein in the spinal cord [25, $61,28]$ in neuropathic pain conditions. In these studies, an up-regulation of CB2 receptors has been found on the activated microglia in the ipsilateral dorsal horn of spinal cord. Another strategy for obtaining analgesia while avoiding the central psychotic effect of cannabinoids is to target the EC turnover such as that of AEA [36], 2-AG [37, 42] and NADA [62,63], whose increase inhibits nociception by acting on CB1 and CB2 receptors [4]. This approach would have the benefit of cannabinoid receptor activation at sites of high EC turnover without interfering with all CB1 receptors which can cause side effects. Indeed, endocannabinoids are synthesized on demand [64] in certain patho-physiological conditions including inflammatory and neuropathic pain $[5$, 65]. In neuropathic pain, changes in the levels of ECs and related compounds have been reported in several regions of ascending and descending pain pathways. Jhaveri and coworkers (2007) have shown that the levels of AEA and another endovanilloid compound $N$-oleoylethanolamine (OEA), but not of 2-AG, were higher in the ipsilateral hindpaw of neuropathic rats, compared to the ipsilateral hindpaw of sham rats. Similarly, levels of AEA and 2AG, but not palmitoyltanolamide PEA, were increased in the spinal cord, PAG and rostral ventromedial medulla (RVM) in neuropathic rats [11]. In the dorsal raphe nucleus, which has reciprocal projections to the PAG, levels of AEA, but not 2-AG, increased in the chronic constriction injury model of neuropathic pain [8]. Collectively, these studies provided evidence that the endocannabinoid system may be a suitable target for neuropathic pain treatment.

\section{NEURON-MICROGLIA AND PATHOLOGICAL PAIN: A PUZZLING NETWORK}

Spinal cord microglial cells are the earlier-activated cell type in response to peripheral inflammation or nerve injury. In physiological conditions, these cells show a "resting" phenotype which is believed to be responsible for the continuous immune surveillance of their milieu [66, 67]. After peripheral nerve injury "resting" microglia quickly change their phenotype and function, a process identified as "microglial activation" (Fig. 1). This activation process consists of distinct cellular functions aimed at repairing damaged neural cells and eliminating debris from the damaged area [68]. Damaged cells release chemo-attractant molecules that both increase the motility (i.e. chemokinesis) and stimulate the migration (i.e. chemotaxis) of microglia, the combination of which recruits the microglia much closer to the damaged cells [69]. Microglial activation in the spinal cord can be promoted by sciatic nerve ligation [70], spinal nerve ligation [71], sciatic nerve inflammation [72], traumatic nerve tran- 

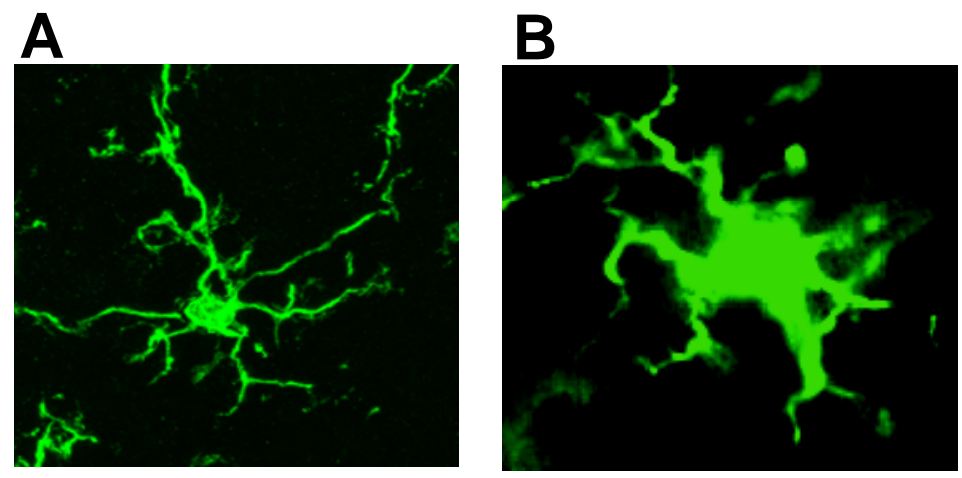

Fig. (1). A confocal image of resting microglia labeled with Iba-1 (A). Single activated microglial cell modified from Luongo et al., 2009 (B).

section [28] and autoimmune diseases such as autoimmune encephalomyelitis and neuritis (EAE, EAN) [73, 74]. Once microglia become activated, they can exert both proinflammatory or anti-inflammatory, neuroprotective functions depending on the combination of the stimulation of several receptors and the expression of specific genes [68, 18]. Thus, the activation of microglia following a peripheral injury can be considered as an adaptation to tissue stress and malfunction [75] that contributes to the development and subsequent maintenance of chronic pain $[61,76]$. Spinal microglia respond quickly to injury, up-regulating cell surface proteins and increasing synthesis and the release of inflammatory mediators, including cytokines and proteases that can sensitize neurons, thereby establishing positive feedback which helps to facilitate nociceptive signalling [77]. Accordingly, the inhibition of microglial targets can reduce hypersensitivity in neuropathic pain states.

The signals responsible for neuronal-microglial and/or astrocytic communication are being extensively investigated as they may represent new targets for chronic pain management. The first candidates are substances released by activated nociceptive primary afferent fibers, such as glutamate and substance $\mathrm{P}$ (SP), which are able to activate microglia [78, 79]. Glutamate activates microglia by stimulating NMDA channels [79], although other mechanisms involving metabotropic glutamate receptors (mGluRs) cannot be ruled out since they appear expressed on microglial cells [80-82]. SP acts mostly by activating microglial neurokinin-1 (NK1) receptors. Many mechanisms have been proposed for neuron-microglia crosstalk. Among these, the fractalkine (FKN, CX3CL1), a member of CX3C class of chemokines and its receptor CX3CR1 have been extensively investigated [83]. FKN is constitutively expressed by spinal cord and sensory neurons in the dorsal root ganglia (DRGs) [84-86], while CX3CR1 is exclusively expressed by microglial cells [85] and, after peripheral nerve injury it is widely up-regulated in microglia [85]. FKN produces nociceptive behaviour by activating CX3CR1 on microglia and p38 mitogen-activated protein kinase (MAPK)-mediated pathways [86, 87]. A mechanism for a cleavage of neuronal membrane-bound FKN has been elegantly demonstrated [86]. Briefly, neuronal FKN is cleaved by cathepsin S (CatS), a proteolitic enzyme, which is expressed and released by activated microglia [86]. Same authors have demonstrated that the liberation of fractalkines in the dorsal horn requires CatS to be released from microglia [88]. However, the CX3CL1/CX3CR1 pathway, which represents a pro-nociceptive non adaptive process seems to perform a neuroprotective role in neurodegenerative diseases [89]. Another candidate for neuronal-microglial crosstalk is ATP, which is produced by neurons as well as by glial cells. ATP exerts its effect by activating the purinergic ionotropic P2X4 and P2X7, as well as the metabotropic $\mathrm{P} 2 \mathrm{Y} 6$ and $\mathrm{P} 2 \mathrm{Y} 12$ receptors on microglia [90]. P2X4 activation seems to be involved in the development of neuropathic pain by inducing the release of brain derived neurotrophic factor (BDNF) [91, 92]. P2X4 receptor activation occurs earlier than that of $\mathrm{P} 2 \mathrm{X} 7$ channel due to the greater affinity of ATP to bind to P2X 4 receptor. Indeed, P2X7 is involved in the maintenance of microglial activation. The $\mathrm{P} 2 \mathrm{X} 7$ receptor appears to be a functionally unique ionotropic receptor among the $\mathrm{P} 2 \mathrm{X}$ receptor family since its activation is able to stimulate the release of the pro-inflammatory cytokine interleukin-1 $\beta$ (IL-1 $\beta$ ), as well as a variety of other proinflammatory cytokines. Recent studies have revealed that P2Y12R is also crucial in neuropathic pain induction and maintenance. It has been found that the expression of P2Y12R mRNA and protein are markedly enhanced in the spinal cord ipsilaterally to spinal nerve injury [93] or to sciatic nerve partial ligation [94]. The cellular location of this receptor in the spinal cord was heavily restricted to microglia and recently has been purported to participate in the motility of microglial cell bodies and processes [95]. It is therefore possible that P2Y12R activity in microglia affects their ability to extend the branched processes toward neighboring neurons of the pain matrix, which, in turn, may interfere with microglia-neuron communications. A metabotropic adenosine receptor $\mathrm{A}_{2 \mathrm{~A}}$ has also been shown to be involved in the microglial process retraction occurring during microglial activation [96]. The up-regulation of Gs protein-coupled adenosine $\mathrm{A}_{2 \mathrm{~A}}$ receptor on activated microglia seems to occur concomitantly to down regulation of Gi-protein coupled P2Y12 receptor [96]. Furthermore, the adenosine A1 and A3 receptors have been found to be expressed in microglial cells [97, 98]. Another chemokine implicated in neuron-glia communication is the chemokine (C-C motif) ligand 2 (CCL2, MCP-1), which is de novo expressed by sensory neurons as early as the day after peripheral injury [99]. Once released, CCL2 activates microglia via interaction with CCR2 receptors, and, accordingly, mice lacking CCR2 receptors display a reduction in nerve injury-induced tactile allodynia [100]. The action of the monocyte chemoattractant protein 1 (MCP-1) at the spinal level has also been demonstrated by the intrathecal 
administration of an MCP-1 neutralizing antibody, which proved able to inhibit neuropathic pain symptoms [99].

\section{ROLE OF ENDOCANNABINOIDS IN NEURON-GLIA INTERACTIONS}

In the complex scenario of neuropathic pain, which involves microglial cell-induced synaptic plasticity, the endocannabinoid system may represent an interesting target for modulating microglia-neuron communication. Indeed, endocannabinoids could be released on demand by neurons as well as by astrocytes and microglial cells [101, 15]. It should be emphasized that microglial cells produce 20 -fold higher amounts of endocannabinoids (expressed in picomoles per nanogram of protein) compared to neurons and astrocytes [15]. In particular, the role of $2-\mathrm{AG}$ in microglial modulation has been investigated $[15,17,28]$. The increased level of 2AG after noxious stimulation has been studied at spinal and supraspinal level in different models of chronic pain [11, 65]. Moreover, analgesic and neuroprotective effects of 2AG have been reported in several models of brain injury $[102,5]$. A recent study has highlighted the neuroprotective effect of 2-AG on the excitotoxic lesion on dentate gyrus granule cells via abnormal-cannabidiol-sensitive receptors on microglial cells [103]. It has been demonstrated that the production of 2-AG in microglial cells is a $\mathrm{Ca}^{2+}$-dependent phenomenon that involves P2X7 receptor activation [104]. Importantly, the EAE model of multiple sclerosis does not lead to an increase in 2-AG [105], although the microglial CB2 receptors are functionally active [106]. This lack of 2-AG increase in the EAE has been explained by the abnormal release of interferon-gamma (IFN $\gamma$ ) due to a $\mathrm{T}$ cell "invasion" of the CNS which, in turn, impairs the functionality of $\mathrm{P} 2 \mathrm{X} 7$ [105]. Intriguingly, 2-AG seems to play a role in the regulation of microglia proliferation and migration. Indeed, it has been shown that microglial cells are able to synthesize this endocannabinoid which increases their proliferation through the activation of $\mathrm{CB} 2$ receptors in vitro [17]. Moreover, 2-AG also stimulates the migration of microglial cells towards dying cells. Once again the CB2 receptors, as well as the abn-CBD receptors on microglia seem to be involved in these mechanisms [15]. Furthermore the role of the endocannabinoids on microglia has been investigated. Navarrete and coworkers have recently shown that NADA is a potent inhibitor of prostaglandin E2 (PGE2) synthesis and of free radical formation in primary lipopolysaccharide (LPS) stimulated microglial cells [107]. Consistently, anandamide is capable of enhancing the anti-inflammatory cytokine interleukin 10 (IL-10) and regulating other cytokine production such as IL-12 and IL-23 in activated microglia by targeting $\mathrm{CB}(2)$ receptors $[108,109]$.

\section{PATHOLOGICAL OR PROTECTIVE: A HAMLETI- CAL QUESTION!}

The pathological and protective roles of glia have recently been reviewed by Milligan and Watkins [76]. A recent study also defined the markers of two distinct phenotypes of microglia, pro-inflammatory (M1) and antiinflammatory (M2) [110]. This evidence provides new tools for investigating the contribution of the immune response in neuropathic pain.

Recent reports, focused on understanding the mechanisms involved in neurodegenerative diseases, have suggested that microglia and astrocytes can also be neuroprotective by releasing several factors that have been demonstrated to have sensitizing actions in neuropathic pain conditions [111]. On this subject, we have already mentioned that the same pronociceptive pathway CX3CL1/CX3CR1 is neuroprotective in neurodegenerative diseases [89]. Both microglia and astrocytes can recognize 'danger signals' and can remove the pathogen or cellular debris through phagocytosis, which also represents the ongoing activity of these cells in healthy conditions. Indeed, astrocytes and microglia express patternrecognition receptors that recognize surface proteins, thus priming the phagocytosis of 'altered' cells. This process seems to be associated with a down-regulation of proinflammatory cytokines to reduce damage to neighboring healthy tissue [112]. On this subject, a study with transgenic $\mathrm{TNF} \alpha$-knockout mice demonstrated that microglial TNF $\alpha$, a known pro-inflammatory cytokine, was critical in the resolution of an inflammatory response and excitotoxic cell death. In addition, while the lack of TNF $\alpha$ reduced microglial activation within 6 hours, an exaggerated microglial activation was measured 4 days later [113]. These data have highlighted not only that a "dark side" of the glia exists, but that in some cases, preventing glial activation in the CNS is undesirable as it could amplify or create pathological pain. Thus, stimulating the anti-inflammatory features of glial activation represents a more powerful approach to controlling pain signaling than exclusively preventing glial activation. With this purpose cannabinoids are being investigated as therapeutic targets for inflammatory neurodegenerative diseases and neuropathic pain for their immunomodulatory properties [27, 28]. , Discrepancies among different studies have however highlighted that further efforts are necessary to be able to include the cannabinoid system in the neuronglia crosstalk during the neuropathic pain establishment. Indeed, evidence that endocannabinoids stimulate the proliferation and migration of microglia may appear in contrast with their anti-inflammatory properties. Indeed, it is worth noting that another anti-inflammatory endogenous lipid mediator, palmitoylethanolamide (PEA), which exerts its action mostly by activating the peroxisome proliferator-activated receptor alpha (PPAR $\alpha)$ [52], is also able to potentiate microglial cell motility [114]. Several studies in recent years have focused on $\mathrm{CB} 2$ receptor activation in different neuropathic pain models $[27,28,115,19]$. Such studies have highlighted the role of $\mathrm{CB} 2$ receptor in the modulation of immune response involved in the development of neuropathic pain. CB2 receptor activation exerts antiallodynic and antihyperalgesic effects by modulating microglial responses. In one of our recent studies [28], we demonstrated that CB2 receptor stimulation induced an analgesic effect associated with a reduction in the pro-inflammatory (IFN- $\gamma$ and IL-1 $\beta$ ) and an enhancement of anti-inflammatory (IL-10) mediators within the spinal cord. In the study, we also demonstrated that the number of microglial profiles was not reduced by a CB2 receptor agonist. Moreover, the two 2-AG biosynthetic enzymes, DAGL $\alpha$ and MGL, were enhanced by the CB2 agonist treatment assuming that an enhanced turnover of 2AG occurs. One can thus speculate that a critical role of endocannabinoids (i.e. 2-AG) on microglia is to shift their phenotype from pro- to anti-inflammatory, and to recruit more anti-inflammatory microglia to the site of injury (Fig. 2) [18]. 


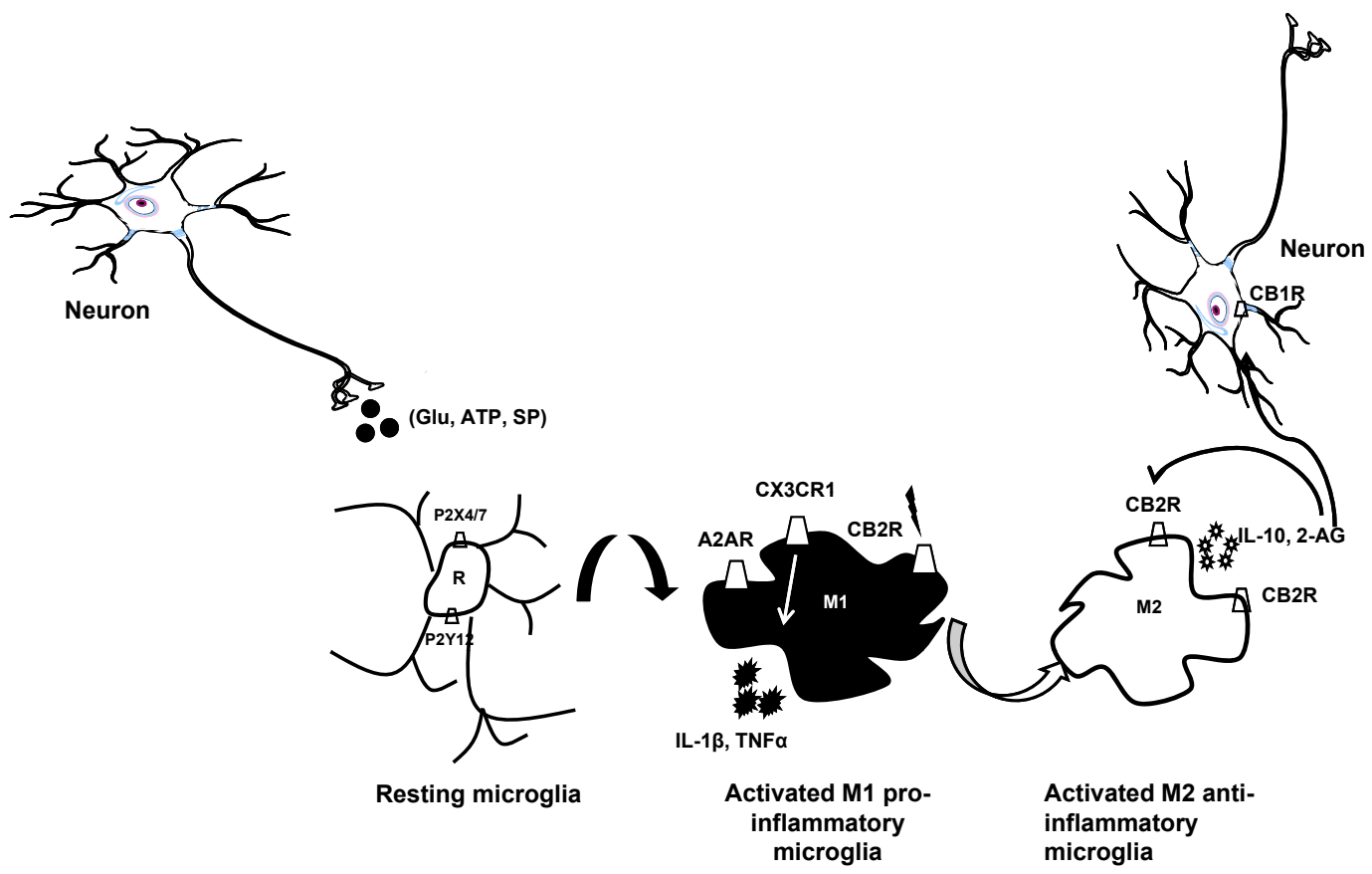

Fig. (2). Rapresentative simplified panel showing resting microglia (blue soma) expressing purinergic receptors (P2X4, P2X7, P2Y12), activated by neuronal substances (ATP, Glu, SP) massively released after peripheral injury. Activated pro-inflammatory microglia M1, showing a morphological change, expresses receptors involved in the active pro-inflammatory state (i.e. CX3CR1, $\mathrm{A}_{2 \mathrm{~A}}$ ), retraction of processes and release of pro-inflammatory cytokines (IL-1 $\beta, \mathrm{TNF} \alpha$ ). Stimulation of CB2 receptors on activated microglia causes a shift from pro- to antiinflammatory phenotype M2 which releases anti-inflammatory (IL-10) and neuroprotective (2-AG) molecules and even further up-regulates CB2 receptor which seems to be critical for recruiting further anti-inflammatory M2 microglia at the site of lesion.

However, several other questions remain unanswered: i) how do CB2 receptor agonists stimulate microglial cell proliferation and/or migration in vivo; ii) what phenotype is the CB2 receptor-recruited microglia; iii) which molecular signals are involved in the microglial phenotypical change expected to be produced in vivo (from pro- to antiinflammatory [68]).

\section{CONCLUSIONS}

The data available on endocannabinoid signaling in glial cells have shown that the endocannabinoid system could be a excellent candidate for the understanding of neuron-glia communication both in physiological and pathological conditions. Moreover, endocannabinoids are also employed in the neurodegenerative diseases associated with motor impairments or demyelinating diseases such as multiple sclerosis $[116,117]$. This could be due to the protective effect of endocannabinoids on oligodendrocytes since their loss is responsible for the progressive demyelination observed in spinal cord injured rats, leading to chronic motor impairment [118]. However, further investigation of the molecular mechanisms involved in the cannabinoid-mediated immune response is needed in order to identify a specific target in managing chronic diseases, such as abnormal pain perception.

\section{ACKNOWLEDGEMENTS}

We are grateful to Prof. Alfonso Barbarisi and Dr. Francesco Rosso for helping us with the confocal microscopy picture of resting microglia (Fig. 1A).

\section{REFERENCES}

[1] Bonica JJ. Pain-basic principles of management. Northwest Med 1970; 69(8): 567-8

[2] Millan MJ.The induction of pain: an integrative review. Prog Neurobiol 1999; 57(1): 1-164.

[3] Goya P, Jagerovic N, Hernandez-Folgado L, Martin MI. Cannabinoids and neuropathic pain. Mini Rev Med Chem 2003; 3(7): 76572.

[4] Cravatt BF, Lichtman AH. The endogenous cannabinoid system and its role in nociceptive behavior 2004. J Neuro Biol 2004; 61(1): $149-160$

[5] Maione S, Bisogno T, de Novellis V, et al. Elevation of endocannabinoid levels in the ventrolateral periaqueductal grey through inhibition of fatty acid amide hydrolase affects descending nociceptive pathways via both cannabinoid receptor type 1 and transient receptor potential vanilloid type-1 receptors. J Pharmacol Exp Ther 2006; 316(3): 969-82.

[6] Pertwee RG. Cannabinoid receptors and pain. Prog Neurobiol 2001; 63(5): 569-611.

[7] Costa B, Trovato AE, Colleoni M, Giagnoni G, Zarini E, Croci T. Effect of the cannabinoid CB1 receptor antagonist, SR141716, on nociceptive response and nerve demyelination in rodents with chronic constriction injury of the sciatic nerve. Pain 2005; 116 (1-2): 52-61.

[8] Palazzo E, de Novellis V, Petrosino S, et al. Neuropathic pain and the endocannabinoid system in the dorsal raphe: pharmacological treatment and interactions with the serotonergic system. Eur J Neurosci 2006; 24(7): 2011-20.

[9] La Rana G, Russo R, Campolongo P, et al. Modulation of neuropathic and inflammatory pain by the endocannabinoid transport inhibitor AM404 [N-(4-hydroxyphenyl)-eicosa-5,8,11,14-tetraenamide]. J Pharmacol Exp Ther 2006; 317(3): 1365-71.

[10] Jhaveri MD, Sagar DR, Elmes SJ, Kendall DA, Chapman V. Cannabinoid CB2 receptor-mediated anti-nociception in models of acute and chronic pain. Mol Neurobiol 2007; 36(1): 26-35. 
[11] Petrosino S, Palazzo E, de Novellis V, et al. Changes in spinal and supraspinal endocannabinoid levels in neuropathic rats. Neuropharmacology 2007; 52(2): 415-22.

[12] Watkins LR, Milligan ED, Maier SF.Spinal cord glia: new players in pain. Pain 2001; 93(3): 201-5.

[13] Carlisle SJ, Marciano-Cabral F, Staab A, Ludwick C, Cabral GA. Differential expression of the $\mathrm{CB} 2$ cannabinoid receptor by rodent macrophages and macrophage-like cells in relation to cell activation. Intern Immunopharmacol 2002; 2: 69-82.

[14] Klegeris A, Bissonnette CJ, McGeer PL. Reduction of human monocytic cell neurotoxicity and cytokine secretion by ligands of the cannabinoid-type CB2 receptor. Br J Pharmacol 2003; 139: 775-786.

[15] Walter L, Franklin A, Witting A, et al. Non-psychotropic cannabinoid receptors regulate microglial cell migration. J Neurosci 2003; 23: $1398-1405$.

[16] Rock RB, Gekker G, Hu S, et al. WIN55,212-2-mediated inhibition of HIV-1 expression in microglial cells: involvement of cannabinoid receptors. J Neuroimmune Pharmacol 2007; 2: 178-183.

[17] Carrier EJ, Kearn CS, Barkmeier AJ, et al. Cultured rat microglial cells synthesize the endocannabinoid 2-arachidonylglycerol, which increases proliferation via a $\mathrm{CB} 2$ receptor-dependent mechanism. Mol Pharmacol 2004; 65(4): 999-1007.

[18] Stella N. Endocannabinoid signaling in microglial cells. Neuropharmacology 2009; 56 Suppl 1: 244-53.

[19] Anand P, Whiteside G, Fowler CJ, Hohmann AG. Targeting CB2 receptors and the endocannabinoid system for the treatment of pain. Brain Res Rev 2009; 60(1): 255-66. 2008

[20] Matsuda LA, Lolait SJ, Brownstein MJ, Young AC, Bonner TI. Structure of a cannabinoid receptor and functional expression of the cloned cDNA. Nature 1990; 346(6284): 561-4.

[21] Munro S, Thomas KL, Abu-Shaar M. Molecular characterization of a peripheral receptor for cannabinoids. Nature 1993; 365(6441): 61-5.

[22] Casu MA, Porcella A, Ruiu S, et al. Differential distribution of functional cannabinoid $\mathrm{CB} 1$ receptors in the mouse gastroenteric tract. Eur J Pharmacol 2003; 459(1): 97-105.

[23] Lange JH, Kruse CG. Keynote review: Medicinal chemistry strategies to CB1 cannabinoid receptor antagonists. Drug Discov Today 2005; 10(10): 693-702.

[24] Van Sickle MD, Duncan M, Kingsley PJ, et al. Identification and functional characterization of brainstem cannabinoid CB2 receptors. Science $2005 ; 310(5746)$ : 329-32.

[25] Zhang J, Hoffert C, Vu HK, Groblewski T, Ahmad S, O'Donnell D. Induction of $\mathrm{CB} 2$ receptor expression in the rat spinal cord of neuropathic but not inflammatory chronic pain models. Eur J Neurosci 2003; 17(12): 2750-4

[26] Maresz K, Carrier EJ, Ponomarev ED, Hillard CJ, Dittel BN. Modulation of the cannabinoid CB2 receptor in microglial cells in response to inflammatory stimuli. J Neurochem 2005; 95(2): 43745 .

[27] Racz I, Nadal X, Alferink J, et al. Crucial role of CB(2) cannabinoid receptor in the regulation of central immune responses during neuropathic pain. J Neurosci 2008; 28(46): 12125-35.

[28] Luongo L, Palazzo E, Tambaro S, et al. 1-(2',4'-dichlorophenyl)-6methyl-N-cyclohexylamine-1,4-dihydroindeno[1,2-c]pyrazole-3carboxamide, a novel CB2 agonist, alleviates neuropathic pain through functional microglial changes in mice. Neurobiol Dis 2010; 37: 177-85.

[29] Johns DG, Behm DJ, Walker DJ, et al. The novel endocannabinoid receptor GPR55 is activated by atypical cannabinoids but does not mediate their vasodilator effects. Br J Pharmacol 2007; 152: 825831 .

[30] Lauckner JE, Jensen JB, Chen HY, Lu HC, Hille B, Mackie K. GPR55 is a cannabinoid receptor that increases intracellular calcium and inhibits M current. Proc Natl Acad Sci USA 2008; 105: 2699-2704.

[31] Oka S, Nakajima K, Yamashita A, Kishimoto S, Sugiura T. Identification of GPR55 as a lysophosphatidylinositol receptor. Biochem Biophys Res Comm 2007; 362: 928-934.

[32] Waldeck-Weiermair M, Zoratti C, Osibow K, et al. Integrin clustering enables anandamide- induced $\mathrm{Ca} 2 \mathrm{p}$ signaling in endothelial cells via GPR55 by protection against CB1-receptor-triggered repression. J Cell Sci 2008; 121: 1704-1717.
[33] Jarai Z, Wagner JA, Varga K, et al. Cannabinoid-induced mesenteric vasodilation through an endothelial site distinct from CB1 or CB2 receptors. Proc Natl Acad Sci USA 1999; 96: 14136-14141.

[34] Offertaler L, Mo F, Ba' tkai S, et al. Selective ligands and cellular effectors of a $\mathrm{G}$ protein-coupled endothelial cannabinoid receptor Mol Pharmacol 2003; 63: 699-705.

[35] Franklin A, Stella N. Arachidonylcyclopropylamide increases microglial cell migration through cannabinoid CB2 and abnormalcannabidiol-sensitive receptors. Eur J Pharmacol 2003; 474: 195198.

[36] Devane WA, Hanus L, Breuer A, et al. Isolation and structure of a brain constituent that binds to the cannabinoid receptor. Science 1992; 258: 1946-1949.

[37] Mechoulam R, Ben-Shabat S, Hanus L, et al. Identification of an endogenous 2- monoglyceride, present in canine gut, that binds to cannabinoid receptors. Biochem Pharmacol 1995; 50: 83-90.

[38] Bouaboula M, Poinot-Chazel C, Bourrie' B, et al. Activation of mitogen-activated protein kinase by stimulation of the central cannabinoid receptor CB1. Biochem J 1995; 312: 637-641.

[39] Felder CC, Briley EM, Axelrod J, Simpson JT, Mackie K, Devane WA. Anandamide, an endogenous cannabimimetic eicosanoid, binds to the cloned human cannabinoid receptor and stimulates receptor-mediated signal transduction. Proc Natl Acad Sci USA 1993; 90: 7656-7660.

[40] Vogel Z, Barg J, Levy R, Saya D, Heldman E, Mechoulam R. Anandamide, a brain endogenous compound, interacts specifically with the cannabinoid receptors and inhibits adenylate cyclase. J Neurochem 1993; 61: 352-355.

[41] Cravatt BJ, Demarest K, Patricelli M, et al. Supersensitivity to anandamide and enhanced endogenous cannabinoid signaling in mice lacking fatty acid amide hydrolase. Proc Natl Acad Sci USA 2001; 98: 9371-9376.

[42] Sugiura T, Kondo S, Sukagawa A, et al. 2-arachidonoylglycerol: a possible endogenous cannabinoid receptor ligand in brain. Biochem Biophys Res Comm 1995; 215: 89-97.

[43] Stella N, Schweitzer P, Piomelli D. A second endogenous cannabinoid that modulates long-term potentiation. Nature 1997; 388: 773 778 .

[44] Beltramo M, Piomelli D. Carrier-mediated transport and enzymatic hydrolysis of the endogenous cannabinoid 2-arachidonylglycerol Neuropharmacology 2000; 11: 1231-1235.

[45] Stella N, Piomelli D. Receptor-dependent formation of endogenous cannabinoids in cortical neurons. Eur J Pharmacol 2001; 425: 189196.

[46] Di Marzo V. Targeting the endocannabinoid system: to enhance or reduce? Nat Rev Drug Discov 2008; 7: 438-455.

[47] Blankman JL, Simon GM, Cravatt BF. A comprehensive profile of brain enzymes that hydrolyze the endocannabinoid 2arachidonoylglycerol. Chem Biol 2007; 14: 1347-1356.

[48] Kozak KR, Rowlinson SW, Marnett LJ. Oxygenation of the endocannabinoid, 2-arachidonylglycerol, to glyceryl prostaglandins by cyclooxygenase-2. J Biol Chem 2000; 275: 33744-33749.

[49] Dixon WE. The pharmacology of cannabis indica. Br Med J 1899; 2: 1354-7.

[50] Thomas H. A community survey of adverse effects of cannabis use. Drug Alcohol Depend. 1996; 42(3): 201-7

[51] Kalant H. Adverse effects of cannabis on health: an update of the literature since 1996. Prog Neuropsychopharmacol Biol Psychiatry 2004; 28(5): 849-63.

[52] Calignano A, La Rana G, Giuffrida A, Piomelli D. Control of pain initiation by endogenous cannabinoids. Nature 1998; 394: 277-281.

[53] Clayton N, Marshall FH, Bountra C, O'Shaughnessy CT. CB1 and CB2 cannabinoid receptors are implicated in inflammatory pain. Pain 2002; 96: 253- 260.

[54] Cheng Y, Hitchcock SA. Targeting cannabinoid agonists for inflammatory and neuropathic pain. Expert Opin Investig Drugs 2007; 16(7): 951-65.

[55] Ibrahim MM, Deng H, Zvonok A, et al. Activation of CB2 cannabinoid receptors by AM1241 inhibits experimental neuropathic pain: pain inhibition by receptors not present in the CNS. Proc Natl Acad Sci USA 2003; 100(18): 10529-33.

[56] Ibrahim MM, Porreca F, Lai J, et al. CB2 cannabinoid receptor activation produces antinociception by stimulating peripheral release of endogenous opioids. Proc Natl Acad Sci USA 2005; 102(8): 3093-8. 
[57] Whiteside GT, Gottshall SL, Boulet JM, et al. A role for cannabinoid receptors, but not endogenous opioids, in the antinociceptive activity of the CB2-selective agonist, GW405833. Eur J Pharmacol 2005 28; 528(1-3): 65-72.

[58] Valenzano KJ, Tafesse L, Lee G, et al. Pharmacological and pharmacokinetic characterization of the cannabinoid receptor 2 agonist, GW405833, utilizing rodent models of acute and chronic pain, anxiety, ataxia and catalepsy. Neuropharmacology 2005; 48(5): 658-72.

[59] Beltramo M, Bernardini N, Bertorelli R, et al. CB2 receptormediated antihyperalgesia: possible direct involvement of neural mechanisms. Eur J Neurosci 2006; 23(6): 1530-8.

[60] Romero-Sandoval A, Eisenach JC. Spinal cannabinoid receptor type 2 activation reduces hypersensitivity and spinal cord glial activation after paw incision. Anesthesiology 2007; 106(4): 787-794.

[61] Romero-Sandoval A, Nutile-McMenemy N, DeLeo JA. Spinal microglial and perivascular cell cannabinoid receptor type 2 activation reduces behavioral hypersensitivity without tolerance after peripheral nerve injury. Anesthesiology 2008; 108(4): 722-734.

[62] Bisogno T, Melck D, Bobrov MY, et al. N-acyl-dopamines: novel synthetic $\mathrm{CB}(1)$ cannabinoid-receptor ligands and inhibitors of anandamide inactivation with cannabimimetic activity in vitro and in vivo. Biochem J 2000; 351 Pt 3: 817-24

[63] Huang SM, Bisogno T, Trevisani M, et al. An endogenous capsaicin-like substance with high potency at recombinant and native vanilloid VR1 receptors. Proc Natl Acad Sci USA 2002; 99(12): 8400-5

[64] Di Marzo V. Endocannabinoids and other fatty acid derivates with cannabimimetic properties: biochemistry and possible physiopathological relevance. Bio Chim Biophys Acta 1998; 1392: 153-175.

[65] Guasti L, Richardson D, Jhaveri M, et al. Minocycline treatment inhibits microglial activation and alters spinal levels of endocannabinoids in a rat model of neuropathic pain. Mol Pain 2009; 5: 35.

[66] Fetler L, Amigorena S. Neuroscience. Brain under surveillance: the microglia patrol. Science 2005; 309: 392-393.

[67] Raivich G. Like cops on the beat: the active role of resting microglia. Trends Neurosci 2005; 28(11):571-3.

[68] Garden GA, Moller T. Microglia biology in health and disease. J Neuroimmune Pharmacol 2006; 1: 127-137.

[69] Trapp BD, Wujek JR, Criste GA, et al. Evidence for synaptic stripping by cortical microglia. Glia 2007; 55: 360-368.

[70] Coyle DE. Partial peripheral nerve injury leads to activation of astroglia and microglia which parallels the development of allodynic behavior. Glia 1998; 23(1): 75-83.

[71] Jin SX, Zhuang ZY, Woolf CJ, Ji RR. p38 mitogen-activated protein kinase is activated after a spinal nerve ligation in spinal cord microglia and dorsal root ganglion neurons and contributes to the generation of neuropathic pain. J Neurosci 2003; 23(10): 4017-22.

[72] Ledeboer A, Sloane EM, Milligan ED, et al. Minocycline attenuates mechanical allodynia and proinflammatory cytokine expression in rat models of pain facilitation. Pain 2005; 115(1-2): 71-83.

[73] Olechowski CJ, Truong JJ, Kerr BJ. Neuropathic pain behaviours in a chronic-relapsing model of experimental autoimmune encephalomyelitis (EAE). Pain 2009; 141(1-2): 156-64.

[74] Luongo L, Sajic M, Grist J, Clark AK, Maione S, Malcangio M. Spinal changes associated with mechanical hypersensitivity in a model of Guillain-Barré syndrome. Neurosci Lett 2008; 437(2): 98102 .

[75] Medzhitov R. Origin and physiological roles of inflammation. Nature 2008; 454(7203): 428-35.

[76] Milligan ED, Watkins LR. Pathological and protective roles of glia in chronic pain. Nat Rev Neurosci 2009; 10(1): 23-36.

[77] Abbadie C, Bhangoo S, De Koninck Y, Malcangio M, MelikParsadaniantz S, White FA. Chemokines and pain mechanisms. Brain Res Rev 2009; 60(1): 125-34.

[78] Lever IJ, Bradbury EJ, Cunningham JR, et al. Brain-derived neurotrophic factor is released in the dorsal horn by distinctive patterns of afferent fiber stimulation. J Neurosci 2001; 21: 4469-4477.

[79] Svensson CI, Hua XY, Protter AA, Powell HC, Yaksh TL. Spinal p38 MAP kinase is necessary for NMDA-induced spinal PGE(2) release and thermal hyperalgesia. Neuroreport 2003a; 14: 11531157.

[80] Taylor DL, Diemel LT, Pocock JM. Activation of microglial group III metabotropic glutamate receptors protects neurons against microglial neurotoxicity. J Neurosci 2003; 23(6): 2150-60.
[81] Taylor DL, Jones F, Kubota ES, Pocock JM. Stimulation of microglial metabotropic glutamate receptor mGlu2 triggers tumor necrosis factor alpha-induced neurotoxicity in concert with microglialderived Fas ligand. J Neurosci 2005; 25(11): 2952-6

[82] Biber K, Laurie DJ, Berthele A, et al. Expression and signaling of group I metabotropic glutamate receptors in astrocytes and microglia. J Neurochem 1999; 72(4): 1671-80.

[83] Milligan ED, Sloane EM, Watkins LR. Glia in pathological pain: a role for fractalkine. J Neuroimmunol 2008; 198: 113-120.

[84] Bazan JF, Bacon KB, Hardiman G, et al. A new class of membrane-bound chemokine with a CX3C motif. Nature 1997; 385: 640-644.

[85] Lindia JA, McGowan E, Jochnowitz N, Abbadie C. Induction of CX3CL1 expression in astrocytes and CX3CR1 in microglia in the spinal cord of a rat model of neuropathic pain. J Pain 2005; 6: 434438.

[86] Clark AK, Yip PK, Grist J, et al. Inhibition of spinal microglial cathepsin $\mathrm{S}$ for the reversal of neuropathic pain. Proc Natl Acad Sci USA 2007; 104: 10655-10660.

[87] Zhuang ZY, Kawasaki Y, Tan PH, WenYR, Huang J, Ji RR. Role of the CX3CR1/p38 MAPK pathway in spinal microglia for the development of neuropathic pain following nerve injury-induced cleavage of fractalkine. Brain Behav Immun 2007; 21: 642- 651

[88] Clark AK, Yip PK, Malcangio M. The liberation of fractalkine in the dorsal horn requires microglial cathepsin S. J Neurosci 2009; 29(21): 6945-54.

[89] Cardona AE, Pioro EP, Sasse ME, et al. Control of microglial neurotoxicity by the fractalkine receptor. Nat Neurosci 2006; 9: 917-924.

[90] Inoue K, Tsuda M, Tozaki-Saitoh H. Modification of neuropathic pain sensation through microglial ATP receptors. Purinergic Signal 2007; 3: 311-316.

[91] Coull JA, Beggs S, Boudreau D, et al. BDNF from microglia causes the shift in neuronal anion gradient underlying neuropathic pain. Nature 2005; 438: 1017-1021.

[92] Ulmann L, Hatcher JP, Hughes JP, et al. Up-regulation of P2X4 receptors in spinal microglia after peripheral nerve injury mediates BDNF release and neuropathic pain. J Neurosci 2008; 28: 1126311268.

[93] Tozaki-Saitoh H, Tsuda M, Miyata H, Ueda K, Kohsaka S, Inoue $\mathrm{K}$. P2Y12 receptors in spinal microglia are required for neuropathic pain after peripheral nerve injury. J Neurosci 2008; 28(19): 494956.

[94] Kobayashi K, Yamanaka H, Fukuoka T, Dai Y, Obata K, Noguchi $\mathrm{K}$. P2Y12 receptor upregulation in activated microglia is a gateway of p38 signaling and neuropathic pain. J Neurosci 2008; 28(11): 2892-902.

[95] Haynes SE, Hollopeter G, Yang G, et al. The P2Y12 receptor regulates microglial activation by extracellular nucleotides. Nat Neurosci 2006; 9(12): 1512-9.

[96] Orr AG, Orr AL, Li XJ, Gross RE, Traynelis SF. Adenosine A(2A) receptor mediates microglial process retraction. Nat Neurosci 2009; 12(7): 872-8.

[97] Synowitz M, Glass R, Färber K, et al. A1 adenosine receptors in microglia control glioblastoma-host interaction. Cancer Res 2006; 66(17): 8550-7.

[98] Hammarberg C, Schulte G, Fredholm BB. Evidence for functional adenosine A3 receptors in microglia cells. J Neurochem 2003; 86(4): 1051-4

[99] Thacker MA, Clark AK, Bishop T, et al. CCL2 is a key mediator of microglia activation in neuropathic pain states. Eur J Pain 2009; 13: 263-272.

[100] Abbadie C, Lindia JA, Cumiskey AM, et al. Impaired neuropathic pain responses in mice lacking the chemokine receptor CCR2. Proc Natl Acad Sci USA 2003; 100: 7947-7952.

[101] Walter L, Franklin A, Witting A, Moller T, Stella N. Astrocytes in culture produce anandamide and other acylethanolamides. J Biol Chem 2002; 277: 20869-20876.

[102] Panikashvili D, Simeonidou C, Ben-Shabat S, et al. An endogenous cannabinoid $(2-A G)$ is neuroprotective after brain injury. Nature 2001; 413(6855): 527-31.

[103] Kreutz S, Koch M, Böttger C, Ghadban C, Korf HW, Dehghani F. 2-Arachidonoylglycerol elicits neuroprotective effects on excitotoxically lesioned dentate gyrus granule cells via abnormalcannabidiol-sensitive receptors on microglial cells. Glia 2009; 57(3): $286-9$ 
[104] Witting A, Walter L, Wacker J, Moller T, Stella N. P2X7 receptors control 2-arachidonoylglycerol production by microglial cells. Proc Natl Acad Sci USA 2004; 101: 3214-3219.

[105] Witting A, Chen L, Cudaback E, et al. Experimental autoimmune encephalomyelitis disrupts endocannabinoid-mediated neuroprotection. Proc Natl Acad Sci USA 2006; 103: 6362-6367.

[106] Areùvalo-Martın A, Vela JM, Molina-Holgado E, Borrell J, Guaza C. Therapeutic action of cannabinoids in a murine model of multiple sclerosis. J Neurosci 2003; 23: 2511-2516.

[107] Navarrete CM, Fiebich BL, de Vinuesa AG, et al. Opposite effects of anandamide and $\mathrm{N}$-arachidonoyl dopamine in the regulation of prostaglandin $\mathrm{E}$ and 8-iso-PGF formation in primary glial cells. $\mathrm{J}$ Neurochem 2009; 109(2): 452-64.

[108] Correa F, Docagne F, Mestre L, et al. A role for CB2 receptors in anandamide signalling pathways involved in the regulation of IL12 and IL-23 in microglial cells. Biochem Pharmacol 2009; 77(1): 86-100.

[109] Correa F, Hernangómez M, Mestre L, et al. Anandamide enhances IL-10 production in activated microglia by targeting $\mathrm{CB}(2)$ receptors: Roles of ERK1/2, JNK, and NF-kappaB. Glia 2010; 58: 13547.

[110] Kigerl KA, Gensel JC, Ankeny DP, Alexander JK, Donnelly DJ, Popovich PG. Identification of two distinct macrophage subsets with divergent effects causing either neurotoxicity or regeneration in the injured mouse spinal cord. J Neurosci 2009; 29: 13435-4.
[111] Glezer A, Simard RS, Rivest S. Neuroprotective role of the innate immune system by microglia. Neuroscience 2007; 147: 867-883.

[112] Elward K, Gasque P. "Eat me" and "don't eat me" signals govern the innate immune response and tissue repair in the CNS: emphasis on the critical role of the complement system. Mol Immunol 2003; 40: 85-94.

[113] Blais V, Rivest S. Effects of TNF- $\alpha$ and IFN- $\gamma$ on nitric oxideinduced neurotoxicity in the mouse brain. J Immunol 2004; 172: 7043-7052.

[114] Franklin A, Parmentier-Batteur S, Walter L, Greenberg DA, Stella N. Palmitoylethanolamide increases after focal cerebral ischemia and potentiates microglial cells motility. J Neurosci 2003; 23 7767-7775.

[115] Romero-Sandoval EA, Horvath R, Landry RP, DeLeo JA. Cannabinoid receptor type 2 activation induces a microglial antiinflammatory phenotype and reduces migration via MKP induction and ERK dephosphorylation. Mol Pain 2009; 5: 25.

[116] Romero J, Orgado JM. Cannabinoids and neurodegenerative diseases. CNS Neurol Disord Drug Targets 2009; 8: 440-50.

[117] Garcia-Ovejero D, Arevalo-Martin A, Petrosino S, et al. The endocannabinoid system is modulated in response to spinal cord injury in rats. Neurobiol Dis 2009; 33: 57-71.

[118] Totoiu MO, Keirstead HS. Spinal cord injury is accompanied by chronic progressive demyelination. J Comp Neurol 2005; 486: 373383.

(C) Luongo et al.; Licensee Bentham Open.

This is an open access article licensed under the terms of the Creative Commons Attribution Non-Commercial License (http://creativecommons.org/licenses/by-nc/3.0/) which permits unrestricted, non-commercial use, distribution and reproduction in any medium, provided the work is properly cited. 